\title{
Family relations of middle-aged citizens in contemporary urban China: a grounded theory approach
}

\author{
Qi Wang \\ Trinity College Dublin, Dublin, Ireland
}

\begin{abstract}
Purpose - Although the Chinese nation is undergoing rapid modernisation and urbanisation, there remains widespread interest in some traditional familial arrangements and practices, particularly in the intergenerational context. This paper discusses the family relations of urban middle-aged citizens in present-day China.

Design/methodology/approach - This study employed the grounded theory method to investigate family relations among middle-aged citizens in urban China based on data obtained via semi-structured interviews with 34 participants. A grounded theory coding strategy was used for data analysis.

Findings - The analysis revealed evidence of a transformation towards downward solidarity, with decreasing intergenerational co-residency; that is, the traditional norm of adult children providing support to their older parents is rapidly losing popularity. However, middle-aged and older citizens continue to support their adult children by helping them purchase real estate and assisting with childcare activities.

Practical implications - The findings suggest the existence of intergenerational inequality. Policymakers should acknowledge this phenomenon and provide the younger generation with enough support to improve the wellbeing of the country's middle-aged and older population.

Originality/value - The transformation towards downward solidarity implies a new intergenerational relationship in contemporary China, in which many young people rely on financial and functional support from their older parents. Meanwhile, traditional norms continue to exist despite greater downward solidarity among the younger generation. In other words, old and new norms simultaneously exist.
\end{abstract}

Keywords Middle-aged, China, Grounded theory, Family relations

Paper type Research paper

\section{Introduction}

In the rapidly changing Chinese society, family relations in contemporary urban China are also undergoing significant shifts. This topic has received substantial attention from sociology researchers. However, existing English-language literature on this issue is limited. Current studies mainly focus on traditional norms and ideologies, with minimal discussion of contemporary family arrangements, such as co-residence and shared childcare activities. Further, only a few studies have used qualitative research methods. More research is needed to examine the relationship between family relations and the economic and political environment of contemporary China. The present study therefore focuses on the family relations of urban middle-aged citizens in contemporary China. It used the constructivist grounded theory (GT) approach to investigate family norms, generational relations and

(C) Qi Wang. Published by Emerald Publishing Limited. This article is published under the Creative Commons Attribution (CC BY 4.0) licence. Anyone may reproduce, distribute, translate and create derivative works of this article (for both commercial and non-commercial purposes), subject to full attribution to the original publication and authors. The full terms of this licence may be seen at http:// creativecommons.org/licences/by/4.0/legalcode

Funding: This research project was funded by the School of Social Work and Social Policy at Trinity College Dublin.

The author is grateful for the feedback and suggestions of Prof Virpi Timonen on this research. Also, the author appreciates the contributions of the research participants to this study.

Received 23 June 2021 Revised 19 August 2021 Accepted 21 August 2021 relations of middle-aged citizens 
IJSSP

$41,13 / 14$

grandparenting activities in the contemporary Chinese context. Using the GT coding strategy, this paper discusses the transformation of Chinese society towards downward solidarity under significant intergenerational inequality. The following section provides some necessary background information on filial piety, co-residence and grandparenting in China to contextualise the present findings.

\section{Background}

Filial piety

The notion of filial piety has not disappeared in China. To the contrary, Chinese parents are becoming more interested in traditional family arrangements (Goossaert and Palmer, 2011). Intergenerational bonds also remain strong in the contemporary context, especially in terms of emotional involvement and mutual support (Jankowiak and Moore, 2017). Research has shown that strong areas of intergenerational support include financial transfers, childcare and housework (Emery et al., 2019), with high-income senior parents being more likely to engage in these exchanges (Emery et al., 2019). Further, traditional ideologies such as filial piety remain prevalent (Hu and Scott, 2016); indeed, the popularity of this concept has not declined, despite changes in other social ideas such as the traditional gender ideology (Hu and Scott, 2016). In sum, the literature shows that filial piety is highly resilient in contemporary China.

The resilience of filial piety in contemporary China challenges modernisation theory (Hu and Scott, 2016), which postulates that economic development and increasing retirement incomes will decrease intergenerational solidarity while weakening the position of older adults in society (Emery et al., 2019). In fact, nearly all participants in a mixed-methods study in China believed that adult children had some degree of responsibility to take care of their senior parents (Warmenhoven et al., 2018). Further, the willingness to do so does not appear to vary based on gender, place of birth or only-child status (Warmenhoven et al., 2018).

Although filial piety is still prevalent in contemporary China, there have been some changes. According to Jankowiak and Moore (2017), unconditional filial piety has disappeared; categorical ethical obligations are being replaced by emotional bonds. In this case, the emotional bonds between senior parents and their adult children form the foundation of filial piety (Jankowiak and Moore, 2017). Further, the weakening of moral constraints has resulted in informality, meaning that familial piety is now primarily based on good personal relationships and the intention to engage in mutual support (Jankowiak and Moore, 2017). In this context, older parents may assist their adult children by paying for education, housing and marriage costs, with the children returning these favours by taking care of their parents in later life. To ensure familial piety, however, parents must also establish emotional ties with their adult children (Jankowiak and Moore, 2017). Indeed, research has shown that emotional closeness and intergenerational support interact with and strengthen each other in China today (Emery et al., 2019).

While it is clear that emotional ties significantly impact intergenerational responsibility, important influences also stem from the separation of values and practices in contemporary China; that is, values and norms are now separate concepts in the Chinese family context (Eklund, 2018). In other words, what people believe or expect may not reflect reality, meaning that intergenerational responsibilities are now more diverse and flexible. The obligations adult children have for their parents therefore depend on their spousal arrangements and work opportunities (Eklund, 2018).

\section{Co-residence and grandparenting}

In contemporary China, a decrease in the frequency of multigenerational co-residence is one of the most obvious changes in filial piety. Today, only one-third of all families in China are 
arranged so that three or more generations live together, with only $43 \%$ of senior citizens living with their adult children (Raymo et al., 2015). This means that most older people in China no longer co-reside with their adult children, and that the tradition of co-residence now only applies to a minority of Chinese elders. In particular, those who are less likely to co-reside include those who have attained higher education, have fewer family members and friends, and live close to medical centres (Liu et al., 2016). Meanwhile, co-residing with adult children is still the preferred living arrangement among the oldest of the elderly (i.e. those over 80 years of age) (Wang et al., 2014). However, married individuals are more likely to live solely with their spouses, with the proportion of this type having increased dramatically between 1982 and 2000 (Wang et al., 2014). In general, this is evidence of Westernisation when it comes to the living arrangements of Chinese elderly persons (Wang et al., 2014).

Many grandparents live with young grandchildren in cases where their adult children are not present, which is a notable divergence from traditional co-residence practices (Chen et al., 2011). In fact, approximately $5 \%$ of Chinese households are "skipped generation" families, in which grandparents live with young grandchildren in the absence of their adult children (Chen et al., 2011). In this regard, it is likely that the grandparents are asked to provide childcare while their adult children work in locations farther away from home. Notwithstanding these circumstances, filial piety continues to exist in other forms. For example, $31 \%$ of senior citizens live in the same neighbourhoods as their children, while $13 \%$ live outside the neighbourhoods but still in the same counties (Raymo et al., 2015). This may indicate that the co-residence tradition is less influential at the individual level but persists in other regards, particularly in cases where living close by is considered sufficient.

Modern grandparenting activities are another example of how traditional Chinese values are changing. In fact, it is contradictory to the conventional notion of filial piety to have grandparents look after their grandchildren. This is because adult children are expected to take care of older people, who, in turn, are not supposed to provide any care services (Chen et al., 2011). According to Ko and Hank (2014), however, grandparenting activities are now prevalent in China, where such engagement has reached $58 \%$, as opposed to only $6 \%$ in South Korea.

Goh (2009) focused on conditions in the coastal city of Xiamen in Southeast China, finding that grandparents played significant roles in raising children. This creates a variety of problems, including reduced time for social networking and related activities, physical exhaustion, and a lack of financial rewards (Goh, 2009); as many grandparents have centred their lives around grandchildren, they must also balance childcare duties with retirement choices and personal hobbies. In fact, Chen et al. (2011) found that many grandparents (especially grandmothers) were providing childcare as frequently as mothers, which requires extensive and burdensome adaptations to meet family needs.

Focusing on the perceptions of grandmothers, Goh and Wang (2019) conducted a comparative study between Singapore and Fuzhou, the latter of which being a city in Southeast China. The researchers found that grandparents in present-day China face substantial cultural expectations to involve themselves in childcare activities and now have fewer cultural resources for expressing either willingness or ambivalence. As a result, most grandmothers who provided childcare in Fuzhou thought the provision was natural. Even for those who did not offer direct childcare, this was primarily because other grandparents were already doing so; however, they still made financial contributions (Goh and Wang, 2019). Meanwhile, most grandmothers disagreed with the notion of intergenerational reciprocity; the wish to remain independent, desire to look after oneself, and increasing acceptance of nursing homes are thus becoming new trends for the elderly in China (Goh and Wang, 2019). In the 2000s, however, the Chinese government "resurrected" Confucian ideas as an aid towards building a "harmonious society", illustrating its intent to promote traditional Chinese culture.

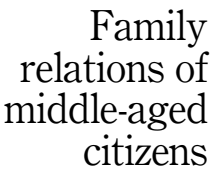

69 
IJSSP

$41,13 / 14$

The current literature on Chinese family relations is mainly focused on traditional values, including filial piety and mutual support between family members. While these topics were reviewed and discussed in this study, I also examined contextual influences on family relations. Notably, the findings add to the literature by clarifying the effects of intergenerational inequality on the formation of family solidarity.

\section{Methods}

GT is a qualitative research method developed during the 1960s by the American scholars Glaser and Strauss (Goulding, 1999). However, there are currently multiple interpretations and understandings of GT. As a result, there is not yet a categorically accepted unified version. Glaser and Strauss even debated this during its development (Goulding, 1999). Later, Oktay (2012) argued for an agnostic position, stating that overreliance on a single model or version may cause GT to lose its character; in this context, a mixed or hybrid model is appropriate. Notably, Charmaz's (2014) contributions to constructivist GT considerably changed the landscape, particularly because of the author's emphasis on the adaptability of research methods. Notably, Timonen et al. (2018) outlined the four core principles of GT: codes and concepts must be grounded in the data, capturing context-related phenomena, pursuing theory through engagement with data, and pursuing theory through theoretical sampling (Timonen et al., 2018). As such, this study used a constructivist GT approach when interviewing respondents about family relations among middle-aged people in urban China. With the aim of generating a new theory, GT provides this research with the tools to achieve a step-by-step theoretical construction. Moreover, this method is particularly suitable because the research on family relations and generational issues in urban China is relatively undeveloped.

More specifically, I conducted semi-structured interviews to clarify the nature of family relations in the context of transitions towards retirement. I therefore prepared a very brief interview guide containing questions about the relationships between parents and their adult children, grandparenting activities, and generational issues. Interviewees were also given opportunities to discuss issues, share stories, and express concerns that they considered essential. Because of the different experiences and personalities of the interviewees, the interview lengths varied significantly; the longest interview lasted over $70 \mathrm{~min}$, while the shortest lasted approximately $20 \mathrm{~min}$. However, most interviews lasted between 40 and $50 \mathrm{~min}$.

A significant issue for this research was the problem of trust in contemporary Chinese society; that is, many people find it challenging to trust individuals with whom they are not well-acquainted. As Li (2010) stated, contrary to the nature of reliance on family members and friends, people tend to distrust those they do not know. In this regard, research fieldwork and interviews may be considered strange and suspicious to potential informants, as many have never heard of qualitative research, which is not widely applied in China. This makes the snowballing sampling strategy highly useful. Although this research project was advertised in relevant neighbourhoods, work settings and on the internet (e.g. WeChat groups), the snowballing strategy was clearly the most efficient approach, as it resulted in the highest number of participants. In fact, many potential interviewees wished to see and talk with the interviewer before consenting to participate in cases where they had no previous social contact with those who helped disseminate information about the research. After these interpersonal discussions, potential respondents were able to develop some level of trust and were thus more likely to consent. This pragmatic usage of snowball sampling was also concurrent with the intended theoretical approach, as desired respondents were expected to share social networks and/or characteristics/circumstances relevant to the research concepts. However, not all recruitment was achieved via snowballing, as some interviewees responded 
to independent invitations to participate; that is, without a prior direct or indirect connection to the interviewer.

Participants included 34 middle-aged citizens who were facing transitions from employment to retirement (17 men and 17 women). The majority were between 40 and 60 years of age (range of 38-68). All participants were initially interviewed, with two being interviewed again at a later time; the interviews were conducted face-to-face with the exception of one individual interview, which was conducted online via audio talk (the interviewee contacted me for a follow-up after I had left the city). All interviews were recorded and transcribed. Because of the inconvenience of conducting fieldwork outside my hometown, including travel and accommodation expenses, poor social contacts, and communication issues stemming from different dialects, most interviews were conducted in Langfang, Hebei province. The main fieldwork site, Langfang is a prefecture-level city (an administrative level between province and county) in Hebei province in the north of China. The human development index of Hebei province in 2016 was 0.735 (UNDP China, 2016). Langfang has a population of over four million (including the populations of the counties in the Langfang region) (Stats.gov.cn, 2019). Langfang is a relatively developed city in Hebei province, and the fieldwork was conducted in urban areas. Thus, the real development stage of the fieldwork site is higher than the average figure for the whole province. While Langfang was selected for pragmatic purposes (access to participants from my home base in China), it also reflects a relatively high-developed urban context in China.

Some participants were sampled from other areas in order to ensure diversity, thus revealing any regional differences (while none were found, this may warrant further research). In sum, interviews were conducted in Shanghai, Jiangsu, Shandong, Hubei, and Sichuan in addition to the main fieldwork site. Unlike the main fieldwork site, which is located in the eastern and northern parts of China, the other research sites covered the southern provinces and western China. Although some participants were currently living or working in Hebei, they were originally from other regions. As a limitation of the sample, the majority of interviewees live in Langfang, and additional participants from other parts of China are needed in further research. Table 1 summarises the key demographic characteristics of the participants.

The above interviewee recruitment process is a good example of theoretical sampling, which is a critical characteristic of GT (Conlon et al., 2020). Initially, I targeted some degree of diversity in regard to gender, employment/retirement status, and living location. The sample and research questions became more focused once the data and concepts began to emerge. For example, the issue of grandparenting frequently arose in discussions with early participants and thus seemed to be a significant concern for the middle-aged and/or a common task for the retired; in other words, it impacted retirement planning and experience. However, no grandparents with direct grandparenting experiences were included in the sample up to that point. Therefore, grandparents who had backgrounds looking after their grandchildren were targeted as sampling proceeded. As such, the relationships between grandparents, grandchildren, and adult children were further investigated in the context of their impingements on retirement planning and retirement experience. Specific issues included retirement incomes and intergenerational equality, the nature of the relationship between parents and their adult children, and the influence of tradition on current family relations. Because of the lack of information in these areas, the contributions from "active" grandparents were considered significant. Another important aspect was pension inequality and the work/retirement choices of the middle-aged population in contemporary China. However, this was not the primary research focus of this paper.

Ethical approval was obtained (via anonymisation for review) based on the standard ethical consideration of "anonymity, confidentiality, informed consent, researchers' potential impact on the participants and vice versa" (Sanjari et al., 2014, p. 14). Participants were also

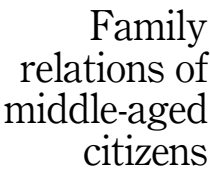




\begin{tabular}{|c|c|c|c|c|c|}
\hline \multirow{7}{*}{$\begin{array}{l}\text { IJSSP } \\
41,13 / 14\end{array}$} & \multirow{2}{*}{ Interview number } & & & & \\
\hline & & Gender & Place of residence & Employment status & Age \\
\hline & 1 & $\mathrm{~F}$ & Hebei & Teacher in primary school & 50 \\
\hline & 2 & $\mathrm{~F}$ & Hebei & Teacher in college & 55 \\
\hline & 3 & $\mathrm{~F}$ & Hebei & Teacher in college & 55 \\
\hline & 4 & $\mathrm{~F}$ & Hebei & Retired enterprise worker & 48 \\
\hline & 5 & $\mathrm{~F}$ & Hebei & Teacher in college & 53 \\
\hline \multirow[t]{26}{*}{72} & 6 & $\mathrm{~F}$ & Hebei & Manager in medical enterprise & 38 \\
\hline & 7 & M & Hebei & Shop owner & 43 \\
\hline & 8 & M & Hebei & Doctor & 53 \\
\hline & 9 & M & Hebei & Public official (retired but went back to work) & 63 \\
\hline & 10 & M & Hebei & Public official (retired but went back to work) & 64 \\
\hline & 11 & M & Hebei & Public official (retired but went back to work) & 64 \\
\hline & 12 & M & Shanghai & Retired enterprise worker & 55 \\
\hline & 13 & $\mathrm{~F}$ & Jiangsu & Administrative worker of a hospital & 54 \\
\hline & 14 & M & Jiangsu & Professor & 48 \\
\hline & 15 & $\mathrm{M}$ & Hubei & Security staff (coming back to work) & 65 \\
\hline & 16 & M & Hubei & Security staff & 58 \\
\hline & 17 & $\mathrm{~F}$ & Hebei & Shop owner & 47 \\
\hline & 18 & M & Shandong & Manager of an enterprise & 49 \\
\hline & 19 & $\mathrm{M}$ & Shandong & Manager of an enterprise & 45 \\
\hline & 20 & $\mathrm{~F}$ & Hebei & Shop owner & 53 \\
\hline & 21 & $\mathrm{~F}$ & Hebei & Retired enterprise worker & 63 \\
\hline & 22 & $\mathrm{~F}$ & Hebei & Retired teacher & 63 \\
\hline & 23 & M & Hebei & Baker & 50 \\
\hline & 24 & M & Hebei & Safety supervision & 58 \\
\hline & 25 & $\mathrm{~F}$ & Hebei & Housewife & 53 \\
\hline & 26 & M & Hebei & Driver & 60 \\
\hline & 27 & $\mathrm{M}$ & Hebei & Warehouse keeper & 68 \\
\hline & 28 & $\mathrm{~F}$ & Hebei & Shop owner & 40 \\
\hline & 29 & $\mathrm{~F}$ & Hebei & Chef & 44 \\
\hline & 30 & M & Hebei & Cleaner & 63 \\
\hline & 31 & $\mathrm{M}$ & Sichuan & Teacher in secondary school & 51 \\
\hline Table 1. & 32 & $\mathrm{~F}$ & Sichuan & Statistician & 40 \\
\hline Summary of & 33 & $\mathrm{~F}$ & Sichuan & Housewife & 50 \\
\hline interviewees & 34 & $\mathrm{~F}$ & Sichuan & Retired factory worker & 53 \\
\hline
\end{tabular}

asked to read information sheets and sign consent forms prior to being interviewed. All participation was voluntary. To protect the confidentiality of interviewees, their real names are not displayed in this paper, as anonymity is typically "provided through the use of pseudonyms" (Halai, 2006, p. 6). Further, all records were stored on a password-protected computer.

In this research, data analysis was conducted in conjunction with the data collection process; that is, the interviews were transcribed, coded, and selectively translated shortly after completion. This facilitated refinements to the interview questions and query methods (Pope et al., 2000), thereby assisting the theoretical sampling process via more targeted questions and respondents.

A GT coding strategy was applied during the data analysis process (Timonen et al., 2018). First, open coding was implemented, in which the data were broken down and coding was accomplished using the gerund forms of relevant verbs, as driven by continually posing the following questions: What is going on here? What are participants relaying? What kinds of actions and experiences are participants conveying? and How do these data relate to the specific inquiry? Second, axial coding was implemented, which "involves rebuilding the data (fractured through open coding) in new ways by establishing relationships between 
categories and their subcategories" (Lawrence and Tar, 2013, p. 32). Third and finally, selective coding was implemented to build a conceptual and theoretical framework. In short, categories, concepts, and theories were successively generated through data analysis. According to Timonen et al. (2018, p. 7), "all coding procedures in GT fundamentally share a common process that results in categories and concepts, and which in turn drives sampling in pursuit of theory".

\section{Findings and discussion}

\section{Continuing influence of traditional ideologies}

In traditional Chinese culture, adult sons are obligated to take care of their ageing parents. Sons in traditional Chinese families are usually raised to ensure their parents' security in old age, which was supported by one participant's response:

Chinese people traditionally raise sons to avoid poverty in old age. I wish my son can first have a stable social position. Subsequently, he can obtain decent [professional] development. He should have a good career in his $30 \mathrm{~s}$. This is the expectation of our generation from our children. I mainly wish him to have a successful career; the success of children is a great support for parents psychologically, is it not? Once I know that my child has done well in his career, I will be happy. A happy and stress-free state is a necessary condition to enjoy later life. Moreover, I also wish that, for example, children can provide some improvement in their parents' economic conditions; that will be rather good. I used to make a joke about that. I used to say that after I retire, you should buy me a car that costs 200 or 300 thousand and a house in a picturesque place with a pleasant climate; since I cannot drive, you will have to hire a chauffeur for me, and that will be enough. I used to make this joke. What does this mean though? Although it was a joke, I still have some financial expectations from him. (Jialing, female, 55, a local college teacher)

The comments of another participant named Guofeng, who is influenced by traditional East Asian culture that emphasises family duties, illustrate the continuing influence of traditional ideologies on contemporary Chinese people, especially the older generation. They like to pass down their ideologies to their children. For instance, Guofeng stated that he would like his son to remember his responsibility towards his family and that his son should have the "intention" to take care of his family:

I do not have too many requirements regarding my child's work. Why? This is because the key to a person's work is the person himself. First, does he have the required ability to do something? Moreover, can others provide him with a platform to enable him to display his ability? I think if he can find a platform to develop his skills through his own efforts, then he can be successful anywhere. Why? I did not keep working in the same place throughout my career. I have worked in Shijiazhuang, Shanxi, as well as Langfang. Every job I had was different from the previous one. Changing jobs can help you challenge yourself; it can also provide opportunities to improve your skills. Thus, he will have a choice. When he builds his career, I may be able to help him to the best of my ability. As a doctor, he may find it difficult to take care of family. I think he should focus on his career first. He should then take responsibility for the family. However, it is important that he must intend to take care of the family. Why? He will be the only man in the family. Taking responsibility for our family, and the small family that he will create in the future, is something that simply must be done. (Guofeng, male, 53, doctor)

\section{Independent relationships between generations}

With the advent of modernisation and related changes in Chinese society, adult children are now playing weaker roles in supporting the elderly. The interviews revealed that, although older parents and their adult children may sometimes require mutual support, independent relationships are often favoured by many middle-aged individuals who are planning to retire. There may be multiple reasons for this phenomenon. In addition to the weakening of

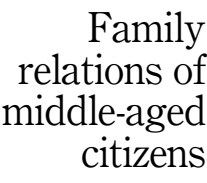


IJSSP

$41,13 / 14$

traditional culture in postmodern society, the currently unbalanced demographic structure may be a significant factor. In this regard, the Chinese government's implementation of the one-child policy has created severe problems for older parents with only one child to provide support. It also poses substantial challenges for children who choose to take care of their parents and grandparents alone. This makes it unrealistic for many older people to entirely rely on support from younger generations. In addition to the 4-2-1 family structure created by the one-child policy, adult children now have significant expenses, as one interviewee reported:

... I really cannot count on them [to take care of me]. You think, [my daughter] herself has two children; she has to struggle to make money, the children will go to school, and she has to think about the tuition fees of the two children. She has to make money. You say, when we really get old and expect them to take care, that will be absolutely impossible. There will be many seniors [to take care of]. Only the generation of parents will have four older people, sometimes including grandmothers and grandfathers. Only two young people ... In addition to two children, there are 10 people altogether. How can the two adults suffer from this? (Wenhua, female, 53, shop owner)

Xueyan, a 40-year-old shop owner, also described a similar situation; as they grow older, their children may not be able to look after them. Such views represent a fundamental transformation in the norms underpinning generational relations - from upward solidarity, flowing predominantly upward towards the older generation, to downward solidarity, from older parents to adult children, involving the appreciation of the need to support the younger generation. Consequently, as Xie and Zhu (2009) argued, upward financial transfers are no longer important and only serve as a symbol of filial piety. In addition to the change in the demographic structure caused by the one-child policy and increased longevity, the greater financial pressure on the younger generation has also contributed to the changing trend of conventional filial piety. Although participants did not explicitly mention the concept of intergenerational equality, they did recognise the serious situation of the younger generation in contemporary China. This phenomenon supports the argument of Timonen et al. (2013) who reported that family members observe each other's situations and accordingly adjust their expectations. In contemporary China, parents' expectations of their children are affected by the changes in the circumstances of the younger generation:

My main post-retirement challenge may be my inability to make enough money. Is this not a practical issue? You say that my son and daughter may be kind to me. In the future, however, my son will have a child; most couples have a child, right? People of our age should have a child. There will then be the two children [the young couple], their own child, in addition to two old people in each family, as well as grandparents, right? There will then be at least four people [to take care of], or five if they have a child. Thus, even though your son is nice to you, he may have the intention but not the ability. He will not have time, will he? Does he not have to work? Does he not need to make a living? Although he would like to take care of you, he will not be able to. For example, our second grandfather and grandmother [father's uncle and aunt] were admitted to a hospital at the same time; they could not take care of themselves. Their family had four adult children, two daughters and two sons; they both had two people each to take care of them. Even then, they could not handle the situation, and they had to hire a nursemaid ... (Xueyan, female, 40, shop owner)

\section{Friendships and security in later life}

As many citizens do not expect their adult children to provide them with security in later life, friendships have become essential among the middle-aged. Indeed, Liyuan's interview responses illustrate the importance of friends when preparing for life after retirement, particularly in regard to the retirement locale itself. Many consider it highly important to live near or with friends who are reliable and share common interests. In this regard, cohabitation 
and mutual support among friends constitutes another old-age security model that also provides senior citizens with vibrant social lives, as Liyuan stated:

\begin{abstract}
... So after I bought an apartment in Langfang, I talked to [friends]; they all bought apartments here. By now, you see, I have gotten used to life here myself. I never cook. Why? We are all together; if we do not go to this home, then we go to that home. So I think we are together; sisters stay together, or some terrific friends stay together; enjoying our later lives as a group is very nice. I have only one child, so in the future, being the only child, she will not have the energy to take care of us. Only if we stay together can we help each other. Therefore, we stayed in Langfang. Langfang is very close to Beijing, and it is very convenient to visit my child. Besides, we live in the same neighbourhood in Langfang, so no matter who comes to visit, we are all together; they are thus free from worry. Therefore, I bought the apartment in Langfang. (Liyuan, female, 47, shop owner)
\end{abstract}

\title{
Grandparenting activities and generational support
}

Pensioners who follow official retirement procedures (including those who retired early) may face the issue of deciding how to use the extra time if they are not occupied by work. In this case, many senior citizens choose to look after their grandchildren as a primary retirement activity. When discussing grandparenting, Shuli, who was working at a hospital at the time of the interview, said it was popular for grandparents to look after babies:

I do not see any young adults nearby who look after their own children without the help of their parents. You see, the young people nearby, or in our working unit ..., nearly all the young people need the help of their parents to look after their children, which is different from our situation in the past. This is because I raised my child on my own when I was young. I think I will not say no if [my daughter] asks for help. As far as I know, she will not rely too much on me. We love children in our family. I think we are all willing to look after the baby, which will not be a problem; we all like children. (Shuli, female, 54, administrative hospital worker)

This phenomenon seems to be the standard model for most families in the current context. It is also a reflection of modern relationships between senior parents and their children. Commonly, young adults now invite their parents to look after their young children in exchange for functional support. On the other hand, ageing parents often contribute time and energy but may not provide financial support to their adult children. Looking at the realities of intergenerational inequality, it is clear that many young adults are fully occupied with their careers and thus rely on ageing parents to contribute to childcare. These conditions are a product of contemporary Chinese society. Another participant named Geng showed an understanding of the present younger generation:

The contemporary young people do not necessarily like their old parents to take care of their children for them. They are unwilling to rely on them if they can [look after their own children]. However, they do not have the required conditions, so they must [rely on the old] depending on their living conditions. If their income cannot support their lives, then they must rely on their old parents, right? Many such situations exist in our school. For example, a young man who lives in Shenzhen bought a flat and is raising a child with the help of his parents. He ranked first in the College Entrance Examination [similar to the SAT] and graduated from Beijing University. He works in a law office. His mother retired early and went to live with him to help him take care of his child, as hiring a maid in Shenzhen would cost more than 10,000 yuan [more than 1,200 euros] . . (Geng, male, 51, teacher)

As Geng stated, young people rely on their parents' support to purchase apartments and take care of their children, as they have no other choice. In fact, this is a structural problem in contemporary China. Young people rely on their parents not because of laziness or incapability but because of economic inequality. Without support from their parents, most young people simply cannot achieve a decent standard of living. Geng provided the example of a young person who graduated from one of the best universities in China and who works as 
IJSSP

$41,13 / 14$

76 a solicitor but still cannot be completely independent, which is the case for most others of his age born in the 1980 and 1990s.

Obviously, grandparenting activities require a significant investment of time for pensioners. This may reduce the opportunities some senior citizens have to achieve other ambitions or engage in hobbies. Even further than this, Goh (2009) argued that grandparenting activities are tiring and unrewarding for senior citizens. Here, the burdens associated with such devotion prevent some middle-aged individuals from becoming involved in these activities. In addition, some older adults simply do not engage in grandparenting and instead expect other relatives to incur the "burden". Jinya stated the following:

I do not want to [take care of grandchildren]. I do not like bringing up children. It is tiring to be with children. In addition, this can make people grow old faster. I am not willing to [do this]. Perhaps, [he should ask] his wife's mother to do this. [Laughing] I used to tell him to marry someone whose parents are healthy. Anyway, I am not going to do this. Bringing up children is quite tiring. It is rather disturbing. (Jinya, female, 50, housewife)

Although this type of support is often given based on the demands of young adults, it may be a choice for some pensioners, who wish to spend their retirement years with grandchildren. For some participants, being with grandchildren creates happiness, as Wanying commented:

Bringing up a child is fun. Ah, when I see the child grow up day after day, I feel that . . .. I do not mean that I have to do it. I just feel that when I get old, I can stay with my child; I am delighted in terms of mood .... If [my son] could bring up his child himself, we could arrange our daily lives. If he could take care of the child, we could go out to play, to exercise together [with her husband] . . . but I will still come to visit my grandchildren regularly. However, when the child grows up, the aspect of education will have to be handled by young people. Older people cannot help with it. This is because the old type of education cannot keep up with [modern education]. The old style will make their education worse. (Wanying, female, 63, retired enterprise worker)

These feelings correspond to the concept of ambivalence in family relations. Normally, this refers to the conflicting expectations senior parents have for their children. Specifically, older parents may expect their children to aim for intergenerational solidarity and independence at the same time (Birditt et al., 2010). Although ambivalence is a separate concept from generational conflict, it is usually related to negative aspects that pertain to offspring. For instance, older parents have fewer ambivalent feelings towards their adult children who are married, better educated, or who hold similar values (Pillemer et al., 2012). Ambivalence is also related to poorer physical health and psychological well-being (Fingerman et al., 2008). Although many Chinese grandparents have ambivalent feelings about childcare, they still report positive effects on their subjective well-being. This shows that the opportunity to be with grandchildren can actually improve their well-being.

However, this does not necessarily mean that grandparents themselves choose or prefer to become involved in these activities. In fact, most participants who looked after grandchildren felt "forced" or at least strongly needed by their adult children. This supports the findings of Goh and Wang (2019) who found that grandparents in contemporary China faced strong cultural expectations to become involved in childcare. Some of the participants in this study said they felt they had no choice, as their families could not find others to help with childcare. Although some participants were able to afford babysitters, they considered it more reasonable to do the work themselves. As Yongqing stated, this is illustrative of the influences imposed by cultural expectations:

... I do not really wish to bring up the child; this is all forced. I do not have other solutions. If I am really heartless, then I could refuse to take care of him. Considering the economic situation of our family, we can afford to send him out [or hire a babysitter]. However, I feel that this may be somewhat 
unreasonable. I think that way ... If I were really unhealthy, I would not do it. However, the essence is that I can do some [work]. Let me tell you something; I now feel tired but happy. Although it was tiring, I am pleased. Bringing up a child is really fun, but I am tired. Sometimes, I really [brave it out]. Taking care of the child consumes a lot of physical strength, running everywhere with the child ... This generation of children is not like the earlier generations who were easy to bring up. The generation of my son, the generation of the only child was difficult to bring up, but this generation is even more difficult to take care of. (Yongqing, female, 63, retired)

\author{
Family \\ relations of \\ middle-aged \\ citizens
}

\section{Conclusions}

This study identified a relatively independent relationship between older parents and their adult children despite the persistence of traditional norms and ideologies. In addition, the analysis revealed a transformation from upward to downward solidarity in contemporary urban China. For example, many senior parents assist their adult children in childcare activities and purchasing apartments, illustrating the older generation's financial and functional support for the younger generation. Such changes in family relations demonstrate the transformation of traditional norms. This finding is consistent with those of relevant studies discussed in this paper. In contemporary China, intergenerational responsibilities have become more flexible and diverse (Eklund, 2018). Although the traditional value of filial piety has not completely disappeared, traditional norms have been adapted to the contemporary urban context. The problem of intergenerational inequality, which has been recognised by some middle-aged and older citizens, has facilitated this transformation to downward intergenerational support as it can successfully limit the negative influence of intergenerational inequality. Meanwhile, this transformation has made many middle-aged and older citizens turn to friends for informal support. Many of them plan to spend their retirement with friends, because they realise that completely relying on their adult children has become unrealistic.

Regarding those currently taking care of their grandchildren, they generally have ambivalent feelings towards their grandparenting experience, describing it as "tiring and happy". However, some participants expressed their unwillingness to engage in grandparenting activities, as it involves sacrificing their personal freedom. Moreover, they believe that young parents should be responsible for taking care of their own children. Nevertheless, they still feel uncertain about whether they will stick to their preference if their adult children ask for their help with childcare in the future. The present findings demonstrate the need and expectation for many grandparents to engage in childcare activities. As grandparenting activities have been a prevalent and integral part of family relations among middle-aged and senior citizens, even those who do not wish to engage in them do need to seriously consider the issue.

This is a qualitative study with limited scope, and hence, I do not aim to generalise its findings and extend them to the entire middle-aged population in contemporary China. Rather, this study contributes to the literature by constructing a theory in which the influence of generational inequality on family relations as well as childcare provisions are highlighted. Therefore, more research is needed to study the impact of intergenerational equality and the formation of family relations in present-day China, for the influence of inequality may have exceeded traditional norms and ideologies. Moreover, more quantitative studies and mixedmethod studies are needed to examine this theory and explore the family relations of those who are in transition to retirement.

As a result of the existence of significant intergenerational inequality and the transformation towards declining solidarity, the relative poverty and dilemma of the younger generation should be addressed by policymakers. The government ought to provide more support to the young people, such as financial support to younger parents. Moreover, the government should put greater efforts into the protection of labour rights, including 
IJSSP

$41,13 / 14$

78

allowing the existence of independent trade unions. However, public discourses on intergenerational inequality should be permitted and promoted by the propaganda department which largely dominates public discussions in present-day China. By acknowledging the existence of this issue, the government can provide more feasible solutions for it. In studies that are based on middle-aged and older citizens, more attention should be paid to the dilemma of the younger generation and the connections between generations. Such research is needed to understand the life choices and family relations of middle-aged and older people.

Since 2019, the COVID-19 pandemic has posed great challenges to the survival of human beings. The lives of most people have changed significantly to adapt to the pandemic and relevant governmental policies such as lockdowns. Some new phenomena regarding intergenerational issues have also occurred since the pandemic. For instance, as Meisner (2020) pointed out, ageism on social media has been exacerbated during the pandemic, and more efforts are needed to fight against ageism. In addition, older people have had different behavioural responses to COVID-19 than the younger generation (Jin et al., 2021). Older people may face higher costs from the virus because of their heightened possibility of experiencing severe symptoms from infection, whereas younger people might suffer more from the lockdown itself (Jin et al., 2021). Obviously, COVID-19 has brought uncertainty to intergenerational issues in contemporary China, and more research is needed to ascertain the effects of the pandemic.

\section{References}

Birditt, K.S., Fingerman, K.L. and Zarit, S.H. (2010), "Adult children's problems and successes: implications for intergenerational ambivalence", The Journals of Gerontology. Series B, Psychological Sciences and Social Sciences, Vol. 65B No. 2, pp. 145-153, doi: 10.1093/geronb/ gbp125.

Charmaz, K. (2014), Constructing Grounded Theory, 2nd ed., Sage, London.

Chen, F., Liu, G. and Mair, C.A. (2011), "Intergenerational ties in context: grandparents caring for grandchildren in China", Social Forces; a Scientific Medium of Social Study and Interpretation, Vol. 90 No. 2, pp. 571-594, doi: 10.1093/sf/sor012.

Conlon, C., Timonen, V., Elliott-O'Dare, C., O'Keeffe, S. and Foley, G. (2020), "Confused about theoretical sampling? Engaging theoretical sampling in diverse grounded theory studies", Qualitative Health Research, Vol. 30 No. 6, pp. 947-959, doi: 10.1177/1049732319899139.

Eklund, L. (2018), "Filial daughter? Filial son? How China's young urban elite negotiate intergenerational obligations", NORA - Nordic Journal of Feminist and Gender Research, Vol. 26 No. 4, pp. 295-312, doi: 10.1080/08038740.2018.1534887.

Emery, T., Dykstra, P. and Djundeva, M. (2019), "Chinese parent-child relationships in later life in the context of social inequalities", Journal of Family Research, Vol. 31 No. 1, pp. 105-124, doi: 10.3224/zff.v31i1.06.

Fingerman, K.L., Pitzer, L., Lefkowitz, E.S., Birditt, K.S. and Mroczek, D. (2008), "Ambivalent relationship qualities between adults and their parents: implications for the well-being of both parties”, The Journals of Gerontology. Series B, Psychological Sciences and Social Sciences, Vol. 63 No. 6, pp. P362-P371, doi: 10.1093/geronb/63.6.P362.

Goh, E. and Wang, S. (2019), "Can Chinese grandparents say no? A comparison of grandmothers in two Asian cities", in Timonen, V. (Ed.), Grandparenting Practices Around the World, 1st ed., Policy Press, Bristol, pp. 233-252. doi: 10.1332/policypress/ 9781447340645.003.0012.

Goh, E.C.L. (2009), "Grandparents as childcare providers: an in-depth analysis of the case of Xiamen, China”, Journal of Aging Studies, Vol. 23 No. 1, pp. 60-68, doi: 10.1016/j.jaging.2007. 08.001 . 
Goossaert, V. and Palmer, D. (2011), The Religious Question in Modern China, 1st ed., The University of Chicago Press, Chicago.

Goulding, C. (1999), "Grounded theory: some reflections on paradigm, procedures and misconceptions", Working paper, University of Wolverhampton, Wolverhampton.

Halai, A. (2006), "Ethics in qualitative research: issues and challenges", Working paper, EdQual, Karachi.

Hu, Y. and Scott, J. (2016), "Family and gender values in China: generational, geographic, and gender differences", Journal of Family Issues, Vol. 37 No. 9, pp. 1267-1293, doi: 10.1177/ $0192513 X 14528710$.

Jankowiak, W. and Moore, R. (2017), Family Life in China, 1st ed., Polity Press, Cambridge.

Jin, S., Balliet, D., Romano, A., Spadaro, G., van Lissa, C., Agostini, M., Bélanger, J., Gützkow, B., Kreienkamp, J. and Leander, N. (2021), "Intergenerational conflicts of interest and prosocial behavior during the COVID-19 pandemic", Personality and Individual Differences, Vol. 171, 110535.

Ko, P.C. and Hank, K. (2014), "Grandparents caring for grandchildren in China and Korea: findings from CHARLS and KLoSA", The Journals of Gerontology. Series B, Psychological Sciences and Social Sciences, Vol. 69 No. 4, pp. 646-651, doi: 10.1093/geronb/gbt129.

Lawrence, J. and Tar, U. (2013), "The use of grounded theory technique as a practical tool for qualitative data collection and analysis", Electronic Journal on Business Research Methods, Vol. 11 No. 1, pp. 29-40.

Li, Y. (2010), "Credit resulted from trust: on the social cause for credit problems", Credit Reference, Vol. 2, pp. 5-8.

Liu, T., Hao, X. and Zhang, Z. (2016), "Identifying community healthcare supports for the elderly and the factors affecting their aging care model preference: evidence from three districts of Beijing", BMC Health Services Research, Vol. 16, p. 626, doi: 10.1186/s12913-016-1863-y.

Meisner, B. (2020), "Are you OK, boomer? intensification of ageism and intergenerational tensions on social media amid COVID-19”, Leisure Sciences, Vol. 43 Nos 1-2, pp. 56-61.

Oktay, J. (2012), Grounded Theory, 1st ed., Oxford University Press, New York.

Pillemer, K., Munsch, C.L., Fuller-Rowell, T., Riffin, C. and Suitor, J.J. (2012), "Ambivalence toward adult children: differences between mothers and fathers", Journal of Marriage and the Family, Vol. 74 No. 5, pp. 1101-1113, doi: 10.1111/j.1741-3737.2012.01004.x.

Pope, C., Ziebland, S. and Mays, N. (2000), "Qualitative research in health care: analysing qualitative data”, BMJ, Vol. 320, pp. 114-116, doi: 10.1136/bmj.320.7227.114.

Raymo, J.M., Park, H., Xie, Y. and Yeung, W.J. (2015), "Marriage and family in East Asia: continuity and change", Annual Review of Sociology, Vol. 41, pp. 471-492, doi: 10.1146/annurev-soc-073014112428.

Sanjari, M., Bahramnezhad, F., Fomani, F.K., Shoghi, M. and Cheraghi, M.A. (2014), "Ethical challenges of researchers in qualitative studies: the necessity to develop a specific guideline", Journal of Medical Ethics and History of Medicine, Vol. 7, p. 14.

Stats.gov.cn (2019), “河北省2010年第六次全国人口普查主要数据公报”, [online] available at: http:// www.stats.gov.cn/tjsj/tjgb/rkpcgb/dfrkpcgb/201202/t20120228_30388.html (accessed 8 June 2019).

Timonen, V., Conlon, C., Scharf, T. and Carney, G. (2013), "Family, state, class and solidarity: re-conceptualising intergenerational solidarity through the grounded theory approach", European Journal of Ageing, Vol. 10 No. 3, pp. 171-179, doi: 10.1007/s10433-013-0272-x.

Timonen, V., Foley, G. and Conlon, C. (2018), "Challenges when using grounded theory: a pragmatic introduction to doing GT research", International Journal of Qualitative Methods, Vol. 17 No. 1, pp. 1-10, doi: 10.1177/1609406918758086.

UNDP China (2016), China National Human Development Report 2016: Social Innovation for Inclusive Human Development, China Publishing Group Corporation, Beijing.
Family
relations of
middle-aged
citizens 
IJSSP

$41,13 / 14$

80
Wang, L., Béland, D. and Zhang, S. (2014), "Pension financing in China: is there a looming crisis?", China Economic Review, Vol. 30, pp. 143-154, doi: 10.1016/j.chieco.2014.05.014.

Warmenhoven, H., Hoebink, P.R.J. and Janssens, J.M.A.M. (2018), "The Chinese postreform generation as caregivers: the caregiving intentions toward parents and parents-in-law of the one-child generation", Journal of Family Issues, Vol. 39 No. 14, pp. 3690-3712, doi: 10.1177/ $0192513 X 18789208$.

Xie, Y. and Zhu, H. (2009), "Do sons or daughters give more money to parents in urban China?", Journal of Marriage and Family, Vol. 71 No. 1, pp. 174-186, doi: 10.1111/j.1741-3737.2008. 00588.x.

\section{Further reading}

Bovenberg, A.L. (2008), "The life-course perspective and social policies: an overview of the issues", CESifo Economic Studies, Vol. 54 No. 4, pp. 593-641, doi: 10.1093/cesifo/ifn029.

\section{Corresponding author}

Qi Wang can be contacted at: wangq9@tcd.ie

For instructions on how to order reprints of this article, please visit our website: 